\title{
Alteration of the expression of sirtuins and var genes by heat shock in the malaria parasite Plasmodium falciparum. a pattern emerges
}

\section{Linda 0. Anagu ( $\sim$ lo.anagu@unizik.edu.ng )}

Department of Pharm. Micro. and Biotech., Nnamdi Azikiwe University, Anambra, 5021, Nigeria https://orcid.org/0000-0002-2243-1616

David R. Hulse

School of Life Sciences, Keele University, Staffordshire, ST5 5BG, UK

\section{Paul D. Horrocks}

School of Medicine, Keele University, Staffordshire, ST5 5BG, UK

Srabasti J Chakravorty

School of Life Sciences, Keele University, Staffordshire, ST5 5BG, UK

\section{Research Article}

Keywords: Plasmodium, var, antigenic variation, sirtuin, Sir2A, Sir2B, heat shock

Posted Date: September 8th, 2021

DOl: https://doi.org/10.21203/rs.3.rs-396479/v3

License: (c) (i) This work is licensed under a Creative Commons Attribution 4.0 International License. Read Full License

Version of Record: A version of this preprint was published at Molecular and Biochemical Parasitology on January 20th, 2022. See the published version at https://doi.org/10.1016/j.molbiopara.2022.111458. 


\section{Abstract \\ Background}

In the malaria parasite Plasmodium falciparum the expression of ' $v a r$ ' virulence genes is regulated through epigenetic mechanisms. $P$. falciparum sirtuin epigenetic regulators have a direct effect on their vargene expression patterns, are increased in the 3D7 laboratory strain on exposure to heat shock. A Gambia study showed an association with fever, blood lactate and var genes commonly expressed in severe malaria, and between PfSir2A and group B var. A Kenyan study extended this association to between PfSir2A and overall vartranscript level. We investigated a causal link between heat shock or lactate levels and sirtuins or var expression.

\section{Methods}

In vitro experiments were conducted using laboratory and recently-laboratory-adapted Kenyan isolates of $P$. falciparum to follow up the correlative findings of the field study. To investigate a potential cause-andeffect relationship between host stress factors and parasite gene expression, qPCR was used to measure the expression of sirtuins and vargenes after highly synchronous cultured parasites had been exposed to $2 \mathrm{~h}$ or $6 \mathrm{~h}$ of heat shock at $40^{\circ} \mathrm{C}$ or elevated lactate.

\section{Results}

Heat shock was shown to increase the expression of PfSir2B in the trophozoites, whereas exposure to lactate was not. After the ring stages were exposed to heat shock and lactate, there was no alteration in the expression of sirtuins and severe-disease-associated upsA and upsB vargenes. The association between high blood lactate and sirtuin/vargene expression that was previously observed in vivo appears to be coincidental rather than causative.

\section{Conclusions}

This study demonstrates that heat stress in laboratory and recently-laboratory-adapted isolates of $P$. falciparum results in a small increase in PfSir $2 B$ transcripts in the trophozoite stages only. This finding adds to our understanding of how patient factors can influence the outcome of Plasmodium falciparum infections.

\section{Background}

Several hundred thousand people die from malaria each year: in 2019, 409,000 deaths were recorded. This is almost always due to infection with the malaria parasite specie $P$. falciparum, which can cause severe and lethal malaria, and children make up $67 \%$ of this mortality (1). Severe malaria manifests as 
three major syndromes: cerebral malaria, acute respiratory distress due to metabolic acidosis and severe anaemia (mainly in young children) (2). Severe malaria is defined by a group of clinical factors including fever of above $39^{\circ} \mathrm{C}(3,4)$ and high blood lactate of $\geq 5 \mathrm{mM}(1,3,5,6)$. Fevers usually last between 2 and 6 $\mathrm{h}$ following a malaria paroxysm (7) while high blood lactate can persist for variable periods (3).

Severe malaria has been associated, in multiple studies, with parasites expressing particular members of the varvirulence gene family (8-14). This is a large family of $\sim 60$ highly variable genes that all encode variants of the protein $P$. falciparum Erythrocyte Membrane Protein 1 (PfEMP1). PfEMP1 is a key virulence factor: it is exported to the surface of parasite-infected erythrocytes, where it mediates adhesion to host cell receptors found on the endothelial lining of blood vessels. Thus, infected erythrocytes can adhere in the microvasculature and avoid splenic clearance (reviewed in (15)). In addition, the host immune system can recognise these PfEMP1 adhesins (16), however, the parasite has evolved to switch their expression regularly $(17,18)$, allowing immune evasion $(19)$, and subsequently persistent and repeated infections $(20,21)$.

Var genes are grouped into the groups upsA, B, C and E based on sequence similarities in their upstream region, as well as their chromosomal location and direction of transcription (22). There appears to be a 'hierarchy' of switching, in which genes of the upsA group, encoding large and complex PfEMP1s that tend to correlate with the severe disease (8-14), are expressed preferentially in immunologically naïve individuals (8). There is some evidence that the upsB group also associates with severe malaria, whereas the upsC group usually does not $(10,11)$.

Vargenes are generally considered to be expressed in a mutually exclusive fashion (18), although this may not be strictly true in all strains $(23,24)$. Mutually exclusive expression means that at any one time, the majority of the family is silenced epigenetically via heterochromatin formation (25). The Plasmodium sirtuins, PfSir2A and B, contribute to this regulation of var expression by enforcing histone deacetylation and thus heterochromatic silencing. Disruption of either sirtuin gene in cultured 3D7 parasites leads to deregulated expression of many vargenes, with PfSir2A primarily controlling the groups upsA, C and E, while PfSir2B primarily controls the upsB group $(26,27)$.

These lines of evidence from in vitro cultured parasites informed a previous study of the correlation between sirtuin and vargene expression in in vivo human infections. qPCR was conducted on parasites directly isolated from Gambian patients with severe or mild malaria, revealing a correlation between elevated expression of PfSir $2 A$ and elevated expression of severe-disease-associated vargenes. This further correlated with patient phenotypes of fever and high blood lactate, leading to the hypothesis that these indictors of host stress might be detected by the parasite and translated, via sirtuin activity, into altered patterns of vargene expression (11). A separate study subsequently conducted on East-African (Kenyan) rather than West-African (Gambian) isolates reproduced the correlation between fever, high PfSir2A expression, low pre-existing anti-PfEMP1 immunity, and - in this study - a generally elevated level of vartranscription rather than the elevation of any particular subgroup (28). 
In this present study, conducted in vitro using recently-culture-adapted parasites, we endeavoured to establish whether the correlations detected in these field studies actually denote cause-and-effect relationships. Thus, indicating strategies evolved by the parasite to survive heat stress when a human host experiences malarial fevers. $P$. falciparum parasites were accordingly subjected to high temperature and high lactate levels in vitro, mimicking the high body temperature and high blood lactate that occur in severe malaria.

\section{Methods}

\section{Parasite lines and culture}

P. falciparum (3D7 (obtained from MR4) and 3 Kenyan strains (obtained from the European Malaria Reagent Repository, 9775, 3518 and 10668)) were cultured in $\mathrm{O}^{+}$erythrocytes obtained from the National Blood Transfusion Service (NBTS, Edgbaston, UK). Cultures were maintained at $4 \%$ haematocrit in Roswell Park Memorial Institute (RPMI) 1640 medium containing $25 \mu \mathrm{g} / \mathrm{ml}$ gentamicin sulphate, $0.2 \%$ sodium bicarbonate (Sigma, USA), 0.2\% Albumax II (Life technologies, New Zealand), and $4.3 \%$ pooled human serum. Standard continuous culturing was carried out for 3D7 as described (29), or with more frequent media changes and at $1 \%$ haematocrit, as described (30) for the Kenyan strains. Staging and parasitaemia were assessed from a thin blood smear stained with Hemacolor ${ }^{\circledR}$ Rapid (VWR, UK). Storage and disposal of blood were in accordance with the Human Tissue Authority (HTA) license held by Keele University.

\section{Synchronization of parasites}

Double sorbitol synchronization was carried out as described (31), either $16 \mathrm{~h}$ apart (for the experiments with trophozoites) or $20 \mathrm{~h}$ apart (for the experiments with rings). A $20 \mathrm{~h}$ apart synchronization was required for the rings so as to ensure that synchrony is not lost as the parasites would have to invade new red blood cells and become rings again prior to the experiments.

\section{Stress treatment of parasites}

Stress treatment were carried out at $4 \%$ haematocrit. Trophozoites at $28 \pm 2$ hours post invasion (hpi) were subjected to high temperature $\left(40^{\circ} \mathrm{C}\right)$ and/or to $5 \mathrm{mM}$ sodium lactate for 2 or $6 \mathrm{~h}$. These stressors were chosen to mimic, respectively, common levels of fever in the human host and the WHO threshold for hyperlactataemia that defines severe malaria (2). For the experiments with the rings, only two parasite strains, 9775 and 3518 were used. They were exposed to these stressors at $2 \pm 2$ hpi for $6 \mathrm{~h}$ only. This level of heat shock was chosen because temperatures above $40^{\circ} \mathrm{C}$ were previously shown to kill most 
mature forms of the asexual stage (32) and in our laboratory [unpublished data]. Control samples, cultured under normal culture conditions, were included for all time points.

After the stress, the medium was completely changed and the cultures were used for transcriptional analysis: total RNA was extracted immediately, and after $10 \mathrm{~h}$ recovery (at $16 \pm 2 \mathrm{hpi}$ in ring-stage experiments only). An aliquot of each culture was also diluted immediately after stress to parasitaemia of $0.5 \%$ (for trophozoites) or $0.1 \%$ (for rings) with $4 \%$ haematocrit in complete media, and this was then cultured for $48 \mathrm{~h}$ (for trophozoites) or $72 \mathrm{~h}$ (for rings) to determine survival rate. The difference in the time to assessment for the two parasite stages is to allow 24 more hours after a whole cycle for the reinvaded rings to develop into trophozoites, when the DNA content can parallel parasite numbers. Growth was then measured by SYBR Green 1-based fluorescence assessment as described below.

\section{SYBR Green 1-based fluorescence assessment}

Growth was assessed using the SYBR Green 1-based fluorescence method (33) by mixing $100 \mu \mathrm{l}$ of the parasite cultures with $100 \mu \mathrm{l}$ of lysis buffer containing SYBR green at a 1:5000 dilution (lysis buffer $=$ $20 \mathrm{mM}$ Tris $\mathrm{pH} 7.5,5 \mathrm{mM}$ EDTA, $0.008 \% \mathrm{v} / \mathrm{v}$ saponin and $0.08 \% \mathrm{v} / \mathrm{v}$ Triton X-100) in the wells of a $96-$ well black plate (CellStar, Greiner-bio-one, Germany) in the dark. The plates were then incubated for $1 \mathrm{~h}$ in the dark and the fluorescence intensity was measured using $490 \mathrm{~nm}$ excitation and 510-570 nm emission filter in a Glomax-Multi Detection System (Promega, UK). Raw fluorescence values were used to determine statistical significance. Survival was calculated using the equation: $(\mathrm{gt} / \mathrm{gc}) \times 100$, where $\mathrm{gt}=$ fluorescence of the test sample and $\mathrm{gc}=$ fluorescence of the control sample.

\section{Gene expression analysis}

Total RNA was extracted from each sample culture as described previously (34), but rather than adding Trizol to the iRBCs, Trizol was added directly to the parasite pellet. Briefly, parasites were released from RBCs by saponin lysis at a concentration of $0.1 \%$, (using equal volume of a $0.2 \%$ solution of saponin to the pelleted blood). Free parasites were briefly washed with ice-cold sterile-filtered 1xPBS. Trizol was then added to the parasite pellet, mixed and incubated for 5 mins at $37^{\circ} \mathrm{C}$ so as to initiate the RNA extraction. The mixture was stored at $-80^{\circ} \mathrm{C}$ and the RNA extraction was completed within 2 weeks of storage. RNA yield was quantified using a Nanospec 1000 (Thermoscientific, USA). Contaminating DNA was removed using the wipe out buffer in the QuantiTect ${ }^{\circledR}$ Reverse Transcription Kit (QIAGEN GmbH, Germany). cDNA was synthesized with this kit and the absence of contaminating genomic DNA was verified by PCR across the intron of the gene PF3D7_0424300, as described previously (35).

Relative gene expression of the sirtuins and vargenes was determined by qPCR in a StepOne Plus ${ }^{\text {TM }}$ Realtime PCR machine (Thermo Fischer Scientific) using SensiFAST ${ }^{\mathrm{TM}}$ SYBR (Bioline, UK), cDNA (diluted at most 1:20) and primers $(0.125 \mu \mathrm{M})$ in a $20 \mu$ reaction volume. Cycling conditions were $50^{\circ} \mathrm{C}$ for $2 \mathrm{~min}$, 
initial denaturation at $95^{\circ} \mathrm{C}$ for $3 \mathrm{~min}$, followed by 40 cycles of denaturation at $95^{\circ} \mathrm{C}$ for $15 \mathrm{~s}$, annealing at $54^{\circ} \mathrm{C}$ for $40 \mathrm{~s}$ and elongation at $60^{\circ} \mathrm{C}$ for $1 \mathrm{~min}$. A melt-curve step was included to verify the specificity of the reactions. Reference genes used as controls were PF3D7_0717700 (serine tRNA-ligase), PF3D7_1444800 (FBP aldolase) and PF3D7_1246200 (actin). In ring-stage samples, the reference genes PF3D7_0501300 (SBP1) and PF3D7_1370300 (MAHRP1) were also measured as previously described (11) to confirm that parasites were consistently ring-staged. Data analysed with the inclusion of these reference genes are in Additional file 3. Primers to the target genes PfSir2A, PfSir2B (11), the major vargene groups (10), and the conserved acidic terminal segment (ATS) of all vargenes (11) were used as published. Primers to PfHsp70 (P1 and P2) and MAHRP1 (P3 and P4) were designed using Snapgene software (Supplemental file 1, Table S1), their specificity was validated and minimal formation of primer-dimers was confirmed. All primers were manufactured and HPSF®-purified by Eurofins mwg®. Primer sequences are in Supplemental file 1 (Tables S2 and S3).

The relative copy number (RCN) of each target gene in each sample was calculated relative to the average of three housekeeping genes. RCN was calculated from $2^{-\Delta C t} . \Delta C$ is the difference between the $\mathrm{Ct}$ (threshold cycle value, also known as quantification cycle $(\mathrm{Cq})$, is the number of PCR cycles at which the fluorescence generated by the PCR product is distinguishable from the background fluorescence) of a target gene and the average $\mathrm{Ct}$ of the three reference genes, as shown in Supplemental file 2 alongside all raw qPCR data. Log10 of the mean RCN is represented in all the gene expression graphs and was calculated from each biological replicate log10 RCN. Mean fold change in expression was calculated from the difference in the log10 mean RCN of the control and stressed groups by determining the inverse of the antilog of their mean difference.

\section{Statistical analysis}

Experiments with the laboratory strain, 3D7, were done in independent biological triplicates (independent here means that a new culture of the same parasite strain was used to set up the same stress experiments on a different day), each measured by qPCR in technical triplicate (technical means that the same culture of a parasite line was analysed three times in different wells after a single stress experiment), thus yielding a total of 3 independent RCN values. Experiments with the three field strains were done in independent biological duplicates, also assessed by qPCR in technical triplicate, thus yielding 2 independent RCN values for each field strain. Statistical analysis was conducted with Minitab 19 for Windows. A General Linear Model was performed with log10 RCN as a response. Dichotomous categorical predictors of time, ( $2 \mathrm{hrs}$ or $6 \mathrm{hrs} / 6 \mathrm{hrs}$ or $16 \mathrm{hrs})$ temperature $\left(37^{\circ}\right.$ or $\left.40^{\circ} \mathrm{C}\right)$ and treatments (LAC $5 \mathrm{mM}$ or none). The log10 RCN values showed no evidence of heteroscedasticity (variances were not significantly different for all groups; the data are spread equally) using Levene's test. Anderson Darling detected some residuals were non-normally distributed, the GLM was assumed to be robust to this as $n$ was greater than 10 (36) (Supplemental file 3). Multiple comparisons were done using Turkey's pairwise comparisons across the categorical predictors. 


\section{Results}

\section{Heat shock adversely affects parasite survival whereas lactate exposure does not}

In order to choose appropriate parameters for exposing parasites to either heat shock or elevated lactate, we first measured parasite survival following such exposures, both at the ring stage and at the trophozoite stage.

$48 \mathrm{~h}$ after sub-culturing the young trophozoites stressed at $28 \pm 4 \mathrm{hpi}$, heat shock at $40^{\circ} \mathrm{C}$ resulted in 0 $23 \%$ death following a $2 \mathrm{~h}$ exposure and $15-43 \%$ death following a $6 \mathrm{~h}$ exposure (Fig. $1 \mathrm{~A}$ ). The extent of heat-shock-induced death appeared strain-dependent, with one strain (9775) appearing more sensitive with a $23 \%$ and $43 \%$ death following 2 and $6 \mathrm{~h}$ of stress respectively (Fig. 1A, green bar). The heat-shockinduced death in the young rings stressed for $6 \mathrm{~h}$ at $2 \pm 2 \mathrm{hpi}$, as calculated from the SYBR Green 1-based fluorescence values $72 \mathrm{~h}$ post-stress (Fig.1B) ranged from $3-27 \%$ similar to trophozoites exposed to heat shock at $40^{\circ} \mathrm{C}$ for $2 \mathrm{~h}$ only thus indicating that the rings are expectedly less sensitive (37). Strain 9775 was equally more sensitive here with $27 \%$ death. This field strain grew to a much higher parasitaemia compared to other strains used in this study when grown in parallel in normal culture conditions at a starting parasitaemia of $0.5 \%$ (data not shown).

By contrast to heat shock, lactate exposure did not appear to have an adverse effect on the survival of the young trophozoites with a 1 - 4\% death after exposure for $2 \mathrm{~h}$ and a $1-12 \%$ death after exposure for $6 \mathrm{~h}$ (Fig.1A). In strains 3D7 and 3518 there was up to a 10\% growth increase compared to the control after 2 $\mathrm{h}$ of stress. Lactate exposure for $6 \mathrm{~h}$ at the ring stage again had little effect on parasite survival and resulted in a $0-7 \%$ death (Fig. 1 B). In the Kenyan strain 9775 there was a $4 \%$ increase in growth. Survival for both parasite stages were similar after exposure to lactate, notwithstanding that the trophozoite is the most metabolically active stage, at which lactate production is highest. When both stressors were applied together, results were very similar to those seen after heat shock alone (Fig. 1A \& B).

\section{Alteration of hsp70, Sir2A and Sir2B expression in heat-shocked trophozoite and ring stages of $P$. falciparum}

Having established the heat shock conditions that caused only a moderate amount of parasite death in both trophozoites and rings, the expression of sirtuin genes immediately after heat shock was measured, as well as the expression of the gene encoding heat shock protein 70 ( $h s p 70)$ as a positive control (Fig. 2 and Table 1). In the trophozoite stage, $h s p 70$ expression was upregulated (Fig. $2 \mathrm{~A}$ ) by 4.70 and 4.92 folds after 6 and $2 \mathrm{~h}$ of heat shock respectively (Table 1) or by 3.42 and 3.69 folds after 6 and $2 \mathrm{~h}$ of heat shock combined with lactate respectively. Expectedly, there was no increase in $h s p 70$ after lactate exposure. 
PfSir2A expression did not change in either trophozoites or rings under any of the conditions tested as it remained the same when time, temperature or treatment factors were used to compare its expression (Fig. 2C, Table 1). PfSir2B expression was increased after $2 \mathrm{~h}$ and $6 \mathrm{~h}$ of heat shock (Fig. 2E) with mean fold changes of 1.88 and 1.98 , respectively (Table 1). Similar to the expression of $h s p 70$, there was also an increase in PfSir $2 B$ after heat shock was combined with lactate with a 1.45 and 1.48 -fold change after $2 \mathrm{~h}$ and $6 \mathrm{~h}$ exposure, respectively. This response was again heat-shock-specific because lactate versus no lactate was not significantly different, thus suggesting that heat shock was the main factor modulating the transcription of PfSir2B.

\section{Table 1}

\section{Fold changes in the expression of hsp70, Sir2A and Sir2B in trophozoites after stress}

\begin{tabular}{|l|l|l|l|}
\hline Gene/Time of exposure & Lactate $5 \mathrm{mM}$ & $\mathbf{4 0}{ }^{\circ} \mathrm{C}$ & $\mathbf{4 0}{ }^{\circ} \mathrm{C}+$ Lactate $5 \mathrm{mM}$ \\
\hline Hsp70 $2 \mathrm{~h}$ & $1.39(0.49$ to 3.89$)$ & $4.92(1.73$ to 14.00$)$ & 3.69 (1.06 to 12.88$)$ \\
\hline Hsp70 $6 \mathrm{~h}$ & $1.06(0.57$ to 1.99$)$ & $4.70(2.06$ to 10.72$)$ & $3.42(1.20$ to 9.76$)$ \\
\hline Sir2A $2 \mathrm{~h}$ & $1.11(0.43$ to 2.87$)$ & $1.37(0.57$ to 3.26$)$ & $1.90(0.64$ to 5.64$)$ \\
\hline Sir2A $6 \mathrm{~h}$ & $1.06(0.42$ to 2.73$)$ & $1.21(0.52$ to 2.87$)$ & $1.23(0.53$ to 2.88$)$ \\
\hline Sir2B $2 \mathrm{~h}$ & $1.28(0.59$ to 2.76$)$ & $1.88(1.11$ to 3.20$)$ & $1.45(0.76$ to 2.77$)$ \\
\hline Sir2B $6 \mathrm{~h}$ & $1.07(0.46$ to 2.49$)$ & $1.98(0.86$ to 4.54$)$ & $1.48(0.49$ to 4.57$)$ \\
\hline
\end{tabular}

Mean (95\% CI) fold changes in the expression of hsp70, Sir2A and Sir2B in trophozoites after a $2 \mathrm{~h}$ or $6 \mathrm{~h}$ exposure to $5 \mathrm{mM}$ Lactate or $40^{\circ} \mathrm{C}$ heat shock, alone or in combination. The calculation of mean fold changes is described in the gene expression analysis subsection in the methods.

The expression of the sirtuins were equally measured immediately after the rings had been exposed to heat shock, elevated lactate, or both stressors combined for $6 \mathrm{~h}$, i.e. expression was measured at $8 \mathrm{hpi}$. Sirtuins expression were also measured at $16 \mathrm{~h}$ (i.e. $10 \mathrm{~h}$ after the stressors were removed), at $18 \mathrm{hpi}-$ around the time of maximum expression for active vargene(s) (38). Only two strains (9775 and 3518) were selected for these experiments as mentioned previously. On exposure of the ring stage parasites to heat shock at $40^{\circ} \mathrm{C}$, hsp 70 was upregulated by an average of 1.98 (heat shock alone) or 1.64 fold (heat shock combined with lactate) after stress (Fig. 2B, Table 2). Sir2A (Fig. 2D) trended upwards both after stress and $10 \mathrm{~h}$ of recovery at $37^{\circ} \mathrm{C}(16 \mathrm{~h}$ after the onset of heat shock), while Sir2B (Fig. 2F) trended 
downwards only after stress, by 2 fold (Table 2, ( 1 divided by 0.47 or 1 divided by 0.49 as it refers to a downregulation). These changes in Sir $2 A$ and Sir2B are not statistically significant.

\section{Table 2}

Fold changes in the expression of hsp $70, \operatorname{Sir} 2 A$ and $\operatorname{Sir} 2 B$ in rings after stress and recovery

\begin{tabular}{|l|l|l|l|}
\hline Gene/Time of exposure & Lactate $5 \mathrm{mM}$ & $\mathbf{4 0} 0^{\circ} \mathrm{C}$ & $\mathbf{4 0}{ }^{\circ} \mathrm{C}+$ Lactate $5 \mathrm{mM}$ \\
\hline Hsp70 $6 \mathrm{~h}$ & $0.62(0.19$ to 2.02$)$ & $1.64(0.61$ to 4.39$)$ & $1.98(0.84$ to 4.67$)$ \\
\hline Hsp70 $16 \mathrm{~h}$ & $0.95(0.57$ to 1.58$)$ & $1.38(0.78$ to 2.46$)$ & $1.19(0.69$ to 2.05$)$ \\
\hline Sir2A $6 \mathrm{~h}$ & $1.02(0.46$ to 2.24$)$ & $1.28(0.64$ to 2.55$)$ & $1.28(0.60$ to 2.74$)$ \\
\hline Sir2A $16 \mathrm{~h}$ & $1.02(0.56$ to 1.87$)$ & $1.49(0.73$ to 3.05$)$ & $1.33(0.64$ to 2.76$)$ \\
\hline Sir2B $6 \mathrm{~h}$ & $0.98(0.35$ to 2.75$)$ & $0.47(0.12$ to 1.95$)$ & $0.49(0.13$ to 1.86$)$ \\
\hline Sir2B $16 \mathrm{~h}$ & $1.01(0.64$ to 1.58$)$ & $1.10(0.72$ to 1.69$)$ & $1.09(0.63$ to 1.87$)$ \\
\hline
\end{tabular}

Mean (95\% CI) fold changes in the expression of hsp70, Sir2A and Sir2B in rings after a 6 $\mathrm{h}$ exposure to $5 \mathrm{mM}$ Lactate or $40^{\circ} \mathrm{C}$ heat shock, alone or in combination, and after a $16 \mathrm{~h}$ recovery from the exposure. The calculation of mean fold changes is described in the gene expression analysis subsection in the methods.

\section{Alteration of var genes expression in P. falciparum ring stages after exposure to heat shock and lactate}

The vargene expression was equally measured in the same ring-staged strains assessed above. Since vargene families are hyper-diverse, var expression was measured using general primer sets that were previously developed to detect conserved regions within each ups-group of vargenes (10). These same primers were used in the study of Gambian field strains which originally reported the association between vargene expression, sirtuin expression, patient fever and hyperlactataemia (11).

Heat shock at $40^{\circ} \mathrm{C}$ and lactate alone or in combination did not lead to a change in the expression of particular or specific vargene groups immediately after $6 \mathrm{~h}$ of stress or after $10 \mathrm{~h}$ of recovery from stress (at $16 \mathrm{~h}$ ) (Fig. 3A-I). Group A vargenes that have been shown to be increasingly expressed in severe malaria were not selectively expressed. All vargene groups were expressed at similar levels in the control and treated/heat shocked parasites. Expectedly, in both the control and stressed rings, the var genes belonging to all the groups except for group $\mathrm{E}$ (var2csa is the only vargene in the group) were 
upregulated after the $10 \mathrm{~h}$ of no stress at $18 \mathrm{hpi}$ ( $\mathrm{p}$ values are not shown for the time categorical factor, see Supplemental file 3) indicating that vargenes are increasingly expressed with time.

\section{Discussion}

This is the first study to use recently laboratory-adapted field strains, in addition to the established laboratory parasite 3D7, to examine links between $P$. falciparum sirtuin expression and elevated temperature, in vitro.

High body temperature and high blood lactate were previously shown to be associated with upregulated sirtuin and var expression in Gambian field isolates of $P$. falciparum causing severe disease (11). In a separate study, fever alone was associated with increased expression of PfSir2A and vargenes in Kenyan field isolates (28). However, cause-and-effect relationships were not established in these studies. We have shown that PfSir2B can be increased in the trophozoites in response to heat shock, but this increase was not more than 2 folds on average. In addition, there was variability between the 3D7 biological replicates (Fig. 2A, first biological replicate showed a slight decrease). There is also a possibility that ring stages may respond to heat shock with a transient downregulation of $P f S i r 2 B$ and an upregulation of $P f S i r 2 A$, but since the experiments involving the rings are less than 5 biological repeats with the 2 strains, the findings here can as best be described as preliminary. It is possible that other factors that occur in in vivo during malaria may act in concert with heat shock to increase the expression of both sirtuins.

In general, the changes in PfSir2B expression were quite modest, and a significant change in the level of a transcript does not necessarily indicate that such change will alter the expression of vargenes or lead to any other biological effect. Possible changes in sirtuin expression, including that of PfSir2B, may correlate with increased expression of vargenes, as has been shown previously in direct patient isolates $(11,28)$. And although we did not see any changes in the expression of PfSir2A, the expression of this sirtuin and vargenes have been shown to be increased in vitro in heat-shocked 3D7 parasites (32). It is possible that we may have missed the time when the 'stress' would have most likely led to an increased expression of Sir $2 A$ or vargenes in the rings as heat shock was applied for a longer time $(6 \mathrm{~h}$ here vs $2 \mathrm{~h}$ in the study referred to). However, it should be considered that the var genes expression here increased across the intraerythrocytic cycle as previously reported (38). That of Sir2A also increases (39). Thus, any increased Sir2A or vargene expression in the heat-shocked 3D7 study may be due to the presence the older parasite stages amongst the asynchronous parasite population used (32). In this study, we have tried to streamline expression profiles by using a highly synchronous parasite population.

In an attempt to validate the absence of any change in Sir2A expression after heat shock, we designed a second independent approach to measure this response https://dx.doi.org/10.17504/protocols.io.btsxnnfn. A luciferase reporter gene was cloned under the presumptive Sir2A promoter ( $1.7 \mathrm{~kb}$ of the gene's upstream sequence). The resulting plasmid, pLNSir2aproluc (Supplemental file 4, Fig. S1A), was transfected into the 3D7 strain and the reporter gene 
was shown to follow an expression profile similar to that of the endogenous Sir2A gene across the intraerythrocytic cycle (39) (Supplemental file 4, Fig. S1B). Unfortunately, this system proved unsuitable for heat shock experiments because the luciferase was severely destabilised at $40^{\circ} \mathrm{C}$ : activity dropped by $\sim 80 \%$ after a $2 \mathrm{~h}$ heat shock, irrespective of the promoter driving luciferase expression (Supplemental file 4 , Fig. S1C), thus obscuring any promoter-mediated regulation at the transcriptional level.

Interestingly, a recent study examining varand $P f S i r 2 A$ expression in parasite-positive individuals in Mozambique showed that PfSir2A transcription was lower in the febrile group than in the afebrile group was published (40). In this study, unlike in the Gambian and Kenyan studies where the subjects were patients that were visiting the hospital or clinic for malaria treatment $(11,28)$, the subjects were identified via a community survey, with none being severely ill or attending a clinic, although some did have an actual or reportedly-recent fever. This observation could suggest that PfSir2A levels may only be significant in cases of more severe and symptomatic disease.

The no change in the expression of vargenes and Sir2A and the very little change in the expression of Sir2B in the parasites in response to heat shock suggests that the host's immune system among other host factors occurring in vivo in severe vs uncomplicated malaria may be involved in the alteration of these genes as observed in the field $(11,28)$. Antibodies have been shown to select against the global expression of vargenes (28) and switching of vargenes do occur as the parasite tries to conceal itself from the host's antibodies $(17,18)$. In addition, specific vargene groups may not be modulated as the expression of a particular vargene by a parasite population is not ideal. Thus, a study attempting to isolate the effect of specific host factors in a parasite population outside the host will be problematic because more than one vargene or vargene group will be expressed in a parasite population.

Conversely, we did not detect any response to elevated lactate levels. This suggests that although high lactate level was clearly identified in a field study as a correlate of sirtuin upregulation (11), the correlation is probably not causative. Alternatively, the level of lactate used here may not have been high enough to see an effect as $5 \mathrm{mM}$ is at and not above, the clinical threshold. Notably, only $26 \%$ of the original patient cohort with severe malaria in the Gambian study (11) had lactate levels $>5 \mathrm{mM}$, suggesting that in vivo this is indeed not common, and aberrantly high.

\section{Conclusion}

Overall, the data presented here suggest that observations made in the West-African field study of patients with severe versus mild malaria (11) do reflect a causative relationship between fever in the human host and expression of PfSir2B in the trophozoite stages, but not between fever and the sirtuins or varvirulence genes in the ring stages. The modest increase of $P f S i r 2 B$ only in the trophozoites and no change in sirtuin or vargenes in the rings indicates a challenge in recapitulating in vivo observations using an in vitro approach. Furthermore, the ability of sirtuin activity to bring about a change in vartranscription directly can be investigated with experiments, such as var gene ChIP for modified histones, or generation of sirtuin knockouts, which would be challenging in newly-cultured field 
strains. Finally, the interplay between $P f S i r 2 A$ and $P f S i r 2 B$ remains uncharacterised and is probably complex.

\section{List Of Abbreviations}

DNA - Deoxyribonucleic acid

EDTA - Ethylenediaminetetraacetic acid Hsp70 - Heat shock protein-70

MR4 - The Malaria Research and Reference Reagent Resource Centre

MSF - Malaria SYBR Green 1-based fluorescence assay

PfEMP1 - P. falciparum Erythrocyte Membrane Protein 1

PBS - Phosphate-buffered saline

PfSir2A - Plasmodium falciparum silent information regulator 2A

PfSir2B - Plasmodium falciparum silent information regulator 2B

RBC - Red blood cell

RNA - Ribonucleic acid

qPCR - quantitative polymerase chain reaction

WHO - World health organization

\section{Declarations}

\section{Ethics approval and consent to participate}

Not applicable. All parasite strains were obtained from registered repositories, rather than directly from human patients. De-identified human erythrocytes in which $P$. falciparum strains were cultured was obtained from the National Blood Service. The use of blood is regulated under the Human Tissues Act 2004 and Keele University is an approved user of the National Blood Service.

\section{Consent for publication}

Not applicable

\section{Availability of data and material}

All data generated or analysed during this study are included in this published article. 


\section{Competing interests}

Declarations of interest: none.

\section{Funding}

This work was majorly funded by the tertiary Education Trust Fund (TETfund) Nigeria. The funders had no role in the study design, data collection and analysis, decision to publish, or preparation of the manuscript.

\section{Authors' contributions}

Linda Anagu: Methodology, Investigation, Formal analysis, Resources, Data Curation, Validation, Writing Original Draft, Writing - Review \& Editing, Visualization, Funding acquisition David Hulse: Formal analysis, Resources Paul Horrocks: Methodology, Resources, Writing - Review \& Editing, Visualization Srabasti Charkravorty: Resources, Project administration, Supervision. All authors read and approved the final manuscript.

\section{Acknowledgements}

We are grateful to Dr. Catherine J Merrick for Conceptualization, Resources, Project administration, Supervision, Methodology, Investigation and Validation of the study, and Writing - Original Draft of the manuscript. Dr. Imran Ullah for help in developing the heat shock experiments.

\section{References}

1. World Health Organization. World Malaria Report 2020 [Internet]. 2020. Available from: https://www.who.int/teams/global-malaria-programme/reports/world-malaria-report-2020

2. World Health Organization. Severe Malaria Supplement [Internet]. WHO; 2014. Available from: https://www.who.int/malaria/publications/atoz/who-severe-malaria-tmih-supplement-2014.pdf

3. Krishna S, Waller DW, Kuile F et al. Lactic acidosis and hypoglycemia in children with severe Malaria: pathophysiological and prognostic significance. Trans R Soc Trop Med Hyg. 1994;(88):67-73.

4. Mockenhaupt FP, Ehrhardt S, Burkhardt J, Bosomtwe SY, Laryea S, Anemana SD, et al. Manifestation and outcome of severe malaria in children in northern Ghana. Am J Trop Med Hyg. 2004 Aug;71(2):167-72.

5. Agbenyega T, Angus BJ, Bedu-Addo G, Baffoe-Bonnie B, Guyton T, Stacpoole PW, et al. Glucose and Lactate Kinetics in Children with Severe Malaria 1. J Clin Endocrinol Metab. 2000;85(4):1569-76.

6. Casals-Pascual C, Kai O, Lowe B, English M, Williams TN, Maitland K, et al. Lactate levels in severe malarial anaemia are associated with haemozoin-containing neutrophils and low levels of IL-12. Malar J. 
2006;5(1):1.

7. Bartoloni A, Zammarchi L. Clinical aspects of uncomplicated and severe malaria. Mediterr J Hematol Infect Dis [Internet]. 2012 Apr;4(1):e2012026-e2012026. Available from: https://www.ncbi.nlm.nih.gov/pubmed/22708041

8. Jensen AT, Magistrado P, Sharp S, Joergensen L, Lavstsen T, Chiucchiuini A, et al. Plasmodium falciparum associated with severe childhood malaria preferentially expresses PfEMP1 encoded by group A var genes. J Exp Med. 2004 May 3;199(9):1179-90.

9. Kyriacou HM, Stone GN, Challis RJ, Raza A, Lyke KE, Thera MA, et al. Differential var gene transcription in Plasmodium falciparum isolates from patients with cerebral malaria compared to hyperparasitaemia. Mol Biochem Parasitol [Internet]. 2006;150(2):211-8. Available from: https://www.ncbi.nlm.nih.gov/pubmed/16996149

10. Rottmann M, Lavstsen T, Mugasa JP, Kaestli M, Jensen AT, Muller D, et al. Differential expression of var gene groups is associated with morbidity caused by Plasmodium falciparum infection in Tanzanian children. Infect Immun. 2006 Jul;74(7):3904-11.

11. Merrick CJ, Huttenhower C, Buckee C, Amambua-Ngwa A, Gomez-Escobar N, Walther M, et al. Epigenetic Dysregulation of Virulence Gene Expression in Severe Plasmodium falciparum Malaria. J Infect Dis [Internet]. 2012;205(10):1593-600. Available from: https://doi.org/10.1093/infdis/jis239

12. Abdi Al, Fegan G, Muthui M, Kiragu E, Musyoki JN, Opiyo M, et al. Plasmodium falciparum antigenic variation: relationships between widespread endothelial activation, parasite PfEMP1 expression and severe malaria. BMC Infect Dis [Internet]. 2014;14:170. Available from:

https://www.ncbi.nlm.nih.gov/pubmed/24674301

13. Storm J, Jespersen JS, Seydel KB, Szestak T, Mbewe M, Chisala N V, et al. Cerebral malaria is associated with differential cytoadherence to brain endothelial cells. EMBO Mol Med [Internet]. 2019;11(2):e9164. Available from: https://www.ncbi.nlm.nih.gov/pubmed/30610112

14. Claessens A, Adams Y, Ghumra A, Lindergard G, Buchan CC, Andisi C, et al. A subset of group Alike var genes encodes the malaria parasite ligands for binding to human brain endothelial cells. Proc Natl Acad Sci U S A. 2012 Jun 26;109(26):E1772-81.

15. Pasternak ND, Dzikowski R. PfEMP1: An antigen that plays a key role in the pathogenicity and immune evasion of the malaria parasite Plasmodium falciparum. Int J Biochem Cell Biol [Internet]. 2009 Jan;41(7):1463-6. Available from:

http://www.sciencedirect.com/science/article/pii/S1357272508005098

16. Newbold Cl, Pinches R, Roberts DJ, Marsh K. Plasmodium falciparum: the human agglutinating antibody response to the infected red cell surface is predominantly variant specific. Exp Parasitol 
[Internet]. 1992;75(3):281-92. Available from: https://pubmed.ncbi.nlm.nih.gov/1426131

17. Roberts DJ, Craig AG, Berendt AR, Pinches R, Nash G, Marsh K, et al. Rapid switching to multiple antigenic and adhesive phenotypes in malaria. Nature [Internet]. 1992;357(6380):689-92. Available from: https://pubmed.ncbi.nlm.nih.gov/1614515

18. Scherf A, Hernandez-Rivas R, Buffet P, Bottius E, Benatar C, Pouvelle B, et al. Antigenic variation in malaria: in situ switching, relaxed and mutually exclusive transcription of var genes during intraerythrocytic development in Plasmodium falciparum. EMBO J [Internet]. 1998;17(18):5418-26. Available from: https://www.ncbi.nlm.nih.gov/pubmed/9736619

19. Abdi Al, Hodgson SH, Muthui MK, Kivisi CA, Kamuyu G, Kimani D, et al. Plasmodium falciparum malaria parasite var gene expression is modified by host antibodies: longitudinal evidence from controlled infections of Kenyan adults with varying natural exposure. BMC Infect Dis [Internet]. 2017;17(1):585. Available from: https://doi.org/10.1186/s12879-017-2686-0

20. Franks S, Koram KA, Wagner GE, Tetteh K, McGuinness D, Wheeler JG, et al. Frequent and Persistent, Asymptomatic Plasmodium falciparum Infections in African Infants, Characterized by Multilocus Genotyping. J Infect Dis [Internet]. 2001;183(5):796-804. Available from: https://doi.org/10.1086/318834

21. Ashley EA, White NJ. The duration of Plasmodium falciparum infections. Malar J [Internet]. 2014;13:500. Available from: https://pubmed.ncbi.nlm.nih.gov/25515943

22. Lavstsen T, Salanti A, Jensen ATR, Arnot DE, Theander TG. Sub-grouping of Plasmodium falciparum 3D7 var genes based on sequence analysis of coding and non-coding regions. Malar $J$ [Internet]. 2003 Oct;2(1):27. Available from: https://doi.org/10.1186/1475-2875-2-27

23. Merrick CJ, Jiang RHY, Skillman KM, Samarakoon U, Moore RM, Dzikowski R, et al. Functional Analysis of Sirtuin Genes in Multiple Plasmodium falciparum Strains. PLoS One [Internet]. 2015;10(3):e0118865. Available from: https://doi.org/10.1371/journal.pone.0118865

24. Joergensen L, Bengtsson DC, Bengtsson A, Ronander E, Berger SS, Turner L, et al. Surface coexpression of two different PfEMP1 antigens on single plasmodium falciparum-infected erythrocytes facilitates binding to ICAM1 and PECAM1. PLoS Pathog [Internet]. 2010 Feb;6(9):e1001083; e1001083e1001083. Available from: https://www.ncbi.nlm.nih.gov/pubmed/20824088

25. Freitas-Junior L, Hernandez-Rivas R, Ralph SA, Montiel-Condado D, Ruvalcaba-Salazar O, RojasMeza A, et al. Telomeric Heterochromatin Propagation and Histone Acetylation Control Mutually Exclusive Expression of Antigenic Variation Genes in Malaria Parasites. Cell [Internet]. 2005 Aug;121(1):25-36. Available from:

http://www.sciencedirect.com/science/article/pii/S0092867405001145 
26. Duraisingh MT, Voss TS, Marty AJ, Duffy MF, Good RT, Thompson JK, et al. Heterochromatin Silencing and Locus Repositioning Linked to Regulation of Virulence Genes in Plasmodium falciparum. Cell [Internet]. 2005;121(1):13-24. Available from: https://doi.org/10.1016/j.cell.2005.01.036

27. Tonkin CJ, Carret CK, Duraisingh MT, Voss TS, Ralph SA, Hommel M, et al. Sir2 paralogues cooperate to regulate virulence genes and antigenic variation in Plasmodium falciparum. PLoS Biol. 2009;7(4):e1000084.

28. Abdi Al, Warimwe GM, Muthui MK, Kivisi CA, Kiragu EW, Fegan GW, et al. Global selection of Plasmodium falciparum virulence antigen expression by host antibodies. Sci Rep [Internet]. 2016;6:19882. Available from: http://10.0.4.14/srep19882

29. R. M. Malaria Methods \& Protocols. Second Edi. London: Humana Press; 2013.

30. Radfar A, MÃ@ndez D, Moneriz C, Linares M, MarÃn-GarcÃa P, Puyet A, et al. Synchronous culture of Plasmodium falciparum at high parasitemia levels. Nat Protoc [Internet]. 2009;4:1899. Available from: http://10.0.4.14/nprot.2009.198

31. Lambros C, Vanderberg JP. Synchronization of Plasmodium falciparum Erythrocytic Stages in Culture. J Parasitol [Internet]. 1979;65(3):418-20. Available from: http://www.jstor.org/stable/3280287

32. Oakley MS, Kumar S, Anantharaman V, Zheng H, Mahajan B, Haynes JD, et al. Molecular factors and biochemical pathways induced by febrile temperature in intraerythrocytic Plasmodium falciparum parasites. Infect Immun. 2007 Apr;75(4):2012-25.

33. Smilkstein M, Sriwilaijaroen N, Kelly JX, Wilairat P, Riscoe M. Simple and inexpensive fluorescencebased technique for high-throughput antimalarial drug screening. Antimicrob Agents Chemother. 2004 May;48(5):1803-6.

34. Taylor HM, Kyes SA, Harris D, Kriek N, Newbold Cl. A study of var gene transcription in vitro using universal var gene primers. Mol Biochem Parasitol. 2000;105(1):13-23.

35. Merrick CJ, Dzikowski R, Imamura H, Chuang J, Deitsch K, Duraisingh MT. The effect of Plasmodium falciparum Sir2a histone deacetylase on clonal and longitudinal variation in expression of the var family of virulence genes. Int J Parasitol. 2010;40(1):35-43.

36. Knief U, Forstmeier W. Violating the normality assumption may be the lesser of two evils. Behav Res Methods [Internet]. 2021; Available from: https://doi.org/10.3758/s13428-021-01587-5

37. Kwiatkowski D. Febrile temperatures can synchronize the growth of Plasmodium falciparum in vitro. J Exp Med [Internet]. 1989 Jan;169(1):357-61. Available from: https://www.ncbi.nlm.nih.gov/pubmed/2642531 
38. Dahlbäck M, Lavstsen T, Salanti A, Hviid L, Arnot DE, Theander TG, et al. Changes in var gene mRNA levels during erythrocytic development in two phenotypically distinct Plasmodium falciparum parasites. Malar J [Internet]. 2007 Dec;6:78. Available from:

https://www.ncbi.nlm.nih.gov/pubmed/17565661

39. Otto TD, Wilinski D, Assefa S, Keane TM, Sarry LR, Bohme U, Lemieux J, Barrell B, Pain A, Berriman $\mathrm{M}$, et al. New insights into the blood-stage transcriptome of Plasmodium falciparum using RNA-Seq. Mol Microbiol 2010, 76:12-24.

40. Gupta H, Galatas B, Matambisso G, Nhamussua L, Cistero P, Bassat Q, Casellas A, Macete E, Aponte $\mathrm{JJ}$, Sacoor $\mathrm{C}$, et al. Differential expression of var subgroups and PfSir2a genes in afebrile Plasmodium falciparum malaria: a matched case-control study. Malar J 2019, 18:326.

\section{Figures}
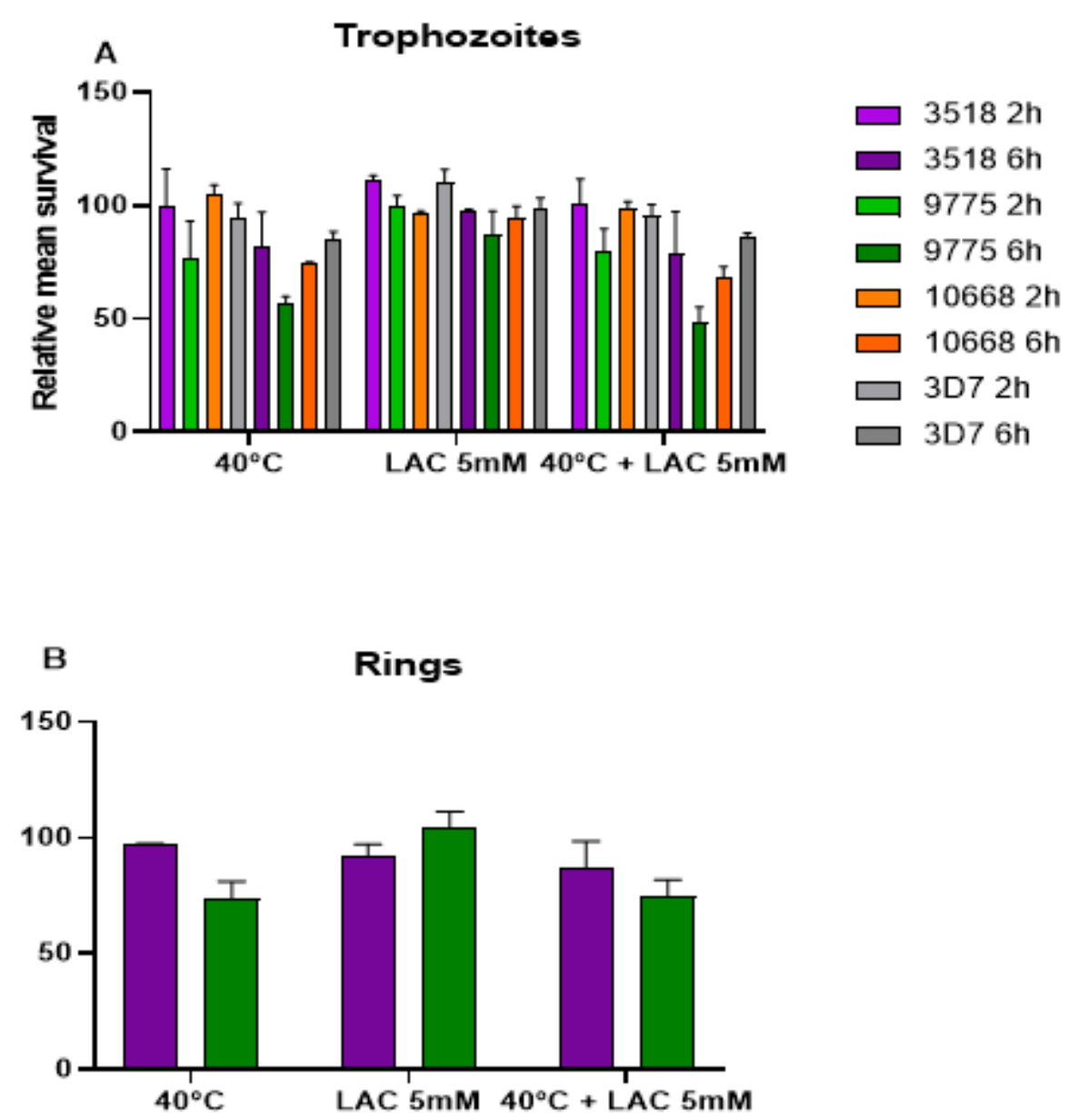

Figure 1

Post-stress survival of P. falciparum after exposure to lactate and heat shock. (colours should be used in print) A. Parasite survival $48 \mathrm{~h}$ after stress treatment for $2 \mathrm{~h}$ or $6 \mathrm{~h}$ at the trophozoite stage, relative to 
growth of a control culture, measured via DNA content in a SYBR-Green-1 based assay. B. Parasite survival $72 \mathrm{~h}$ after stress treatment for $6 \mathrm{~h}$ at the ring stage, relative to growth of a control culture, measured via DNA content in a SYBR-Green-1 based assay. Blue bars, 3D7; red bars, 3518; green bars, 9775; purple bars, 10668. Mean survival rates are from biological duplicates for the Kenyan strains, or triplicates for 3D7. Error bars represent standard error.
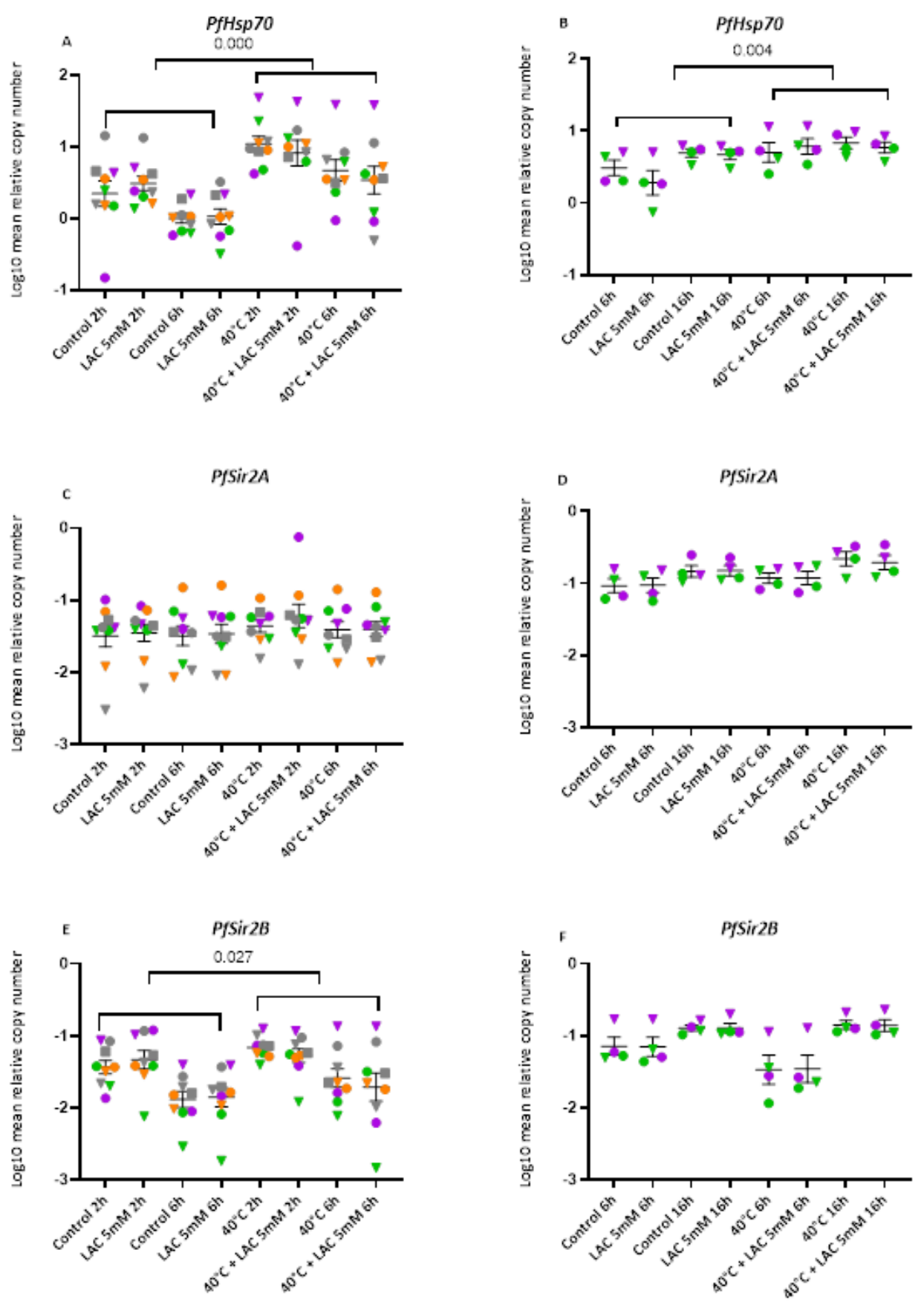

\section{Figure 2}

Altered expression of Hsp70 and PfSir2B in response to heat shock in P. falciparum. (colours should be used in print) Log10 mean relative copy number of Hsp70 in trophozoites (A) or rings (B), Sir2A in trophozoites (C) or rings (D) and Sir2B in trophozoites (E) or rings (F) stages of parasites after stress 
treatments. Grey, purple, green and orange are data from strains 3D7, 3518, 9775 and 10668, respectively. Circles, inverted triangles and squares are data from the first, second and third biological replicate experiments respectively. Error bars show standard error mean (SEM). Significance was determined by fitting a general linear model with Turkey's pairwise comparisons across the categorical predictor of temperature $\left(37^{\circ}\right.$ or $\left.40^{\circ} \mathrm{C}\right)$. In the trophozoites, $p=0.000$ for Hsp70 and $p=0.027$ for Sir $2 \mathrm{~B}$, while in the rings, $\mathrm{p}=0.004$ for Hsp70.
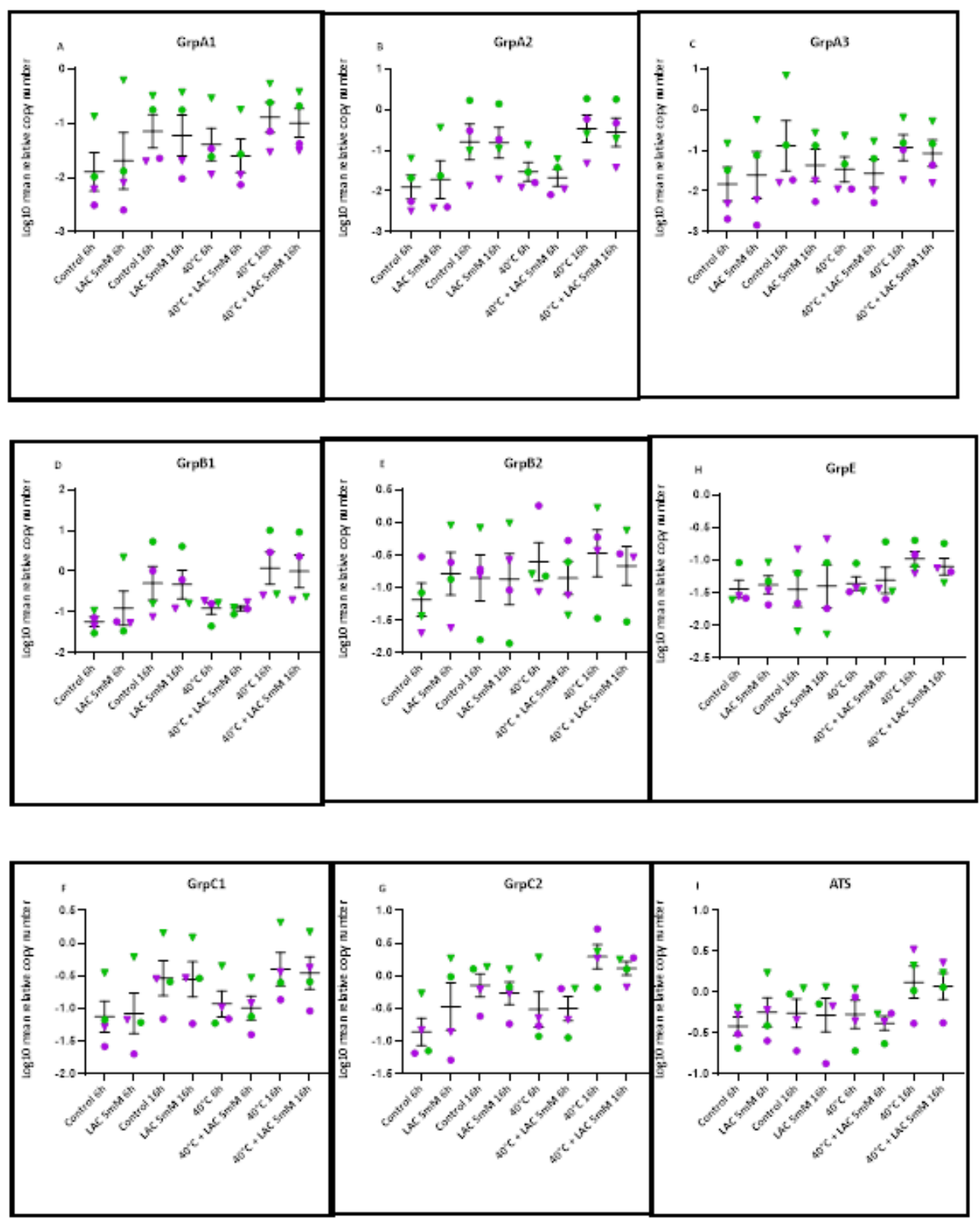

\section{Figure 3}

Var gene expression in ring stage of parasites after 6 hours of stress followed by recovery for 10 hours in P. falciparum. (colours should be used in print) Log10 mean relative copy number of GrpA1 (A), GrpA2 (B) (B) GrpA3 (C), GrpB1 (D), GrpB2 (E), GrpC1 (F), GrpC2 (G), GrpE (H) var genes and their ATS (I) in parasites after $6 \mathrm{~h}$ of stress treatments and after a further $10 \mathrm{~h}$ of no stress ('recovery', at $16 \mathrm{~h}$ from the time the stress was applied). Purple and green are data from strains 3518 and 9775, respectively. Circles and 
inverted triangles are data from the first and second biological replicate experiments respectively. Error bars show standard error mean (SEM). Significance was determined by fitting a general linear model with Turkey's pairwise comparisons across the categorical predictor of temperature $\left(37^{\circ}\right.$ or $\left.40^{\circ} \mathrm{C}\right)$.

\section{Supplementary Files}

This is a list of supplementary files associated with this preprint. Click to download.

- Supplementalfile1.docx

- Supplementalfile2.xlsx

- Supplementalfile3.pptx

- Supplementalfile4.pdf 